Campitelli, G., \& Gobet, F. (in press). The role of practice in chess: A longitudinal study. Learning and Individual Differences.

\title{
The Role of Practice in Chess: A Longitudinal Study
}

\author{
Guillermo Campitelli and Fernand Gobet* \\ Centre for the Study of Expertise \\ Centre for Cognition and Neuroimaging \\ Brunel University \\ Uxbridge, Middlesex, UB8 3PH \\ United Kingdom
}

*Corresponding author

Email: Fernand.Gobet@ brunel.ac.uk

Phone: +44 (1895) 265484

Fax: $\quad+44(1895) 237573$

Running head: The role of practice in chess: A longitudinal study 


\begin{abstract}
We investigated the role of practice in the acquisition of chess expertise by submitting a questionnaire to 104 players of different skill levels. Players had to report their chess rating, the number of hours of individual and group practice, their use of different learning resources and activities, and whether they had been trained by a coach. The use of archival data enabled us to track the rating of some of the players throughout their career. We found that there was a strong correlation between chess skill and number of hours of practice. Moreover, group practice was a better predictor of high-level performance than individual practice. We also found that masters had a higher chess rating than expert players after only three years of serious dedication to chess, although there were no differences in the number of hours of practice. The difference that may explain the variation in rating is that masters start practising at an earlier age than experts. Finally, we found that activities such as reading books and using computer software (game databases, but not playing programs) were important for the development of high-level performance. Together with previous data and theories of expert performance, our results indicate limits in the deliberate practice framework and make suggestions on how best to carry out learning in chess and in other fields.
\end{abstract}

Keywords: chess, chunking, coaching, expertise, individual differences, learning, variability, practice 


\section{The Role of Practice in Chess: A Longitudinal Study}

Learning high-level cognitive skills such as those of senior scientists, virtuosic composers, and chess masters typically requires one to acquire a vast and meaningful knowledge base and engage in situations in which this knowledge base is used. For example, senior scientists should acquire knowledge of the results, theories, and methodologies related to their field of research by reading scientific journals; virtuosic composers should acquire knowledge related to previous compositions with their different styles by reading scores and listening to masterpieces; and chess masters should acquire knowledge of previous master games by replaying them. Moreover, they all have to use their knowledge in performance situations. For example, senior scientists have to design experiments, carry them out, analyse the results, and write reports; virtuosic composers have to create music; and chess masters have to play games. Participating in these situations reorganises the knowledge base and incorporates new information to it.

Research into the acquisition of high-level cognitive abilities has raised a number of issues that are still waiting for a definite answer. Probably the first and most debated of these issues is whether the acquisition of high-level skills is only a matter of the amount of dedication to the domain of expertise or whether innate factors are involved as well. This debate has two extreme views: the first states that talent is the main factor (Galton, 1869/1979), and the other maintains that all skills are acquired through the interaction with the environment (e.g., Watson 1924). Ericsson, Krampe and Tesch-Romer (1993) have revived the latter view with their "deliberate practice" framework, which postulates that not every type of practice leads to expert performance, but only practice that is performed with the deliberate purpose of improving one's own skill. Deliberate practice consists of activities deliberately 
designed to improve performance, which are typically effortful and not enjoyable. These activities cannot be extended throughout long periods and must therefore be limited to a few hours a day. Moreover, Charness, Krampe and Mayr (1996), Charness, Tuffiash, Krampe, Reingold and Vasyukova (2005), and Ericsson et al. (1993) identified individual practice as critical to the development of expertise. On the other hand, Gobet and Campitelli (2007) found that group practice is also relevant to acquire chess expertise.

Assuming that practice is an essential aspect of the acquisition of high-level cognitive skills, a second issue arises: do all individuals benefit to the same extent from practice? This issue was investigated nearly 100 years ago by Thorndike (1908), who suggested a relation between inter-individual variability in performance and the nature of the task. He suggested that if inter-individual variability in performance increases with increasing practice in a particular domain, then the task performed is one that requires factors not related to practice (i.e., innate factors). On the other hand, if inter-individual variability in performance decreases with increasing practice, then this is a sign that practice is the main factor to perform the task. Ackerman's (1987) literature review showed that, in most studies, inter-individual variability in fact decreased, a pattern of results that supports the role of practice.

A third issue revolves around the type of activities that are useful for acquiring high-level cognitive skills. In particular, is it important first to engage in activities leading to the creation of a vast internal knowledge base, and only then to participate in performance situations? Or, alternatively, should the participation in performance situations start early on in the learning process? Perhaps surprisingly, Ericsson et al. (1993) excluded activities in a performance situation from their definition of deliberate practice. In a study with chess players, Charness, Krampe and Mayr (1996) 
followed Ericsson et al.'s (1993) decision and suggested that individual practice is more related to deliberate practice than group practice. (Tournament games were considered as group practice in Charness et al.'s definition.).

Research into expertise has enriched practice in education, for example through the concepts of adaptive expertise, pattern recognition, chunking, and selective search (Anderson, Reder \& Simon, 2000; Baxter \& Glaser, 1998; Gobet, 2005; Gobet \& Wood, 1999; Hatano \& Inagaki, 1986; Simon, 1980). Similarly, understanding the three issues introduced above would have strong implications for education. For example, it would help teachers and coaches to choose appropriate teaching and training activities.

In this paper, we address these three issues by studying practice behaviour in chessplayers. Chess has already considerably enriched our understanding of problem solving (e.g., Campitelli \& Gobet, 2004; Charness, 1981; Gobet, 1998a), imagery (e.g., Campitelli \& Gobet, 2005; Saariluoma, 1991), perception (Charness, Reingold, Pomplun, \& Stampe, 2001; De Groot \& Gobet, 1996), memory (e.g., Chase \& Simon, 1973; Cooke, Atlas, Lane \& Berger, 1993; Gobet \& Simon, 1996a, b) and other psychological phenomena (see Gobet, de Voogt \& Retschitzki, 2004, for a review). Chess has several advantages that make it a powerful task for studying cognitive processes and learning (see Gobet, 1998b). For the purpose of this study, three of these advantages are essential. First, it is a complex game that requires many years of practice to attain high levels. Second, the existence of an international rating scale allows researchers to know the level of expertise of their participants with precision. Third, the existence of archival data of chess players' ratings makes it possible to track their level of expertise throughout their careers. 
A large sample of Argentinian players had to fill out a questionnaire similar to that used by Charness et al. (1996), as well as the Edinburgh Handedness Inventory (Oldfield, 1971; the handedness data are discussed in Gobet \& Campitelli, 2007, which also addresses the question of starting age). The results allowed us to systematically address the three issues identified in the introduction. First, we addressed the hypothesis that individuals' current performance is directly related to the amount of deliberate practice; we refined this question by studying individual and group practice separately. Second, we addressed the role of inter-individual variability in the acquisition of chess expertise, again considering both individual and group practice. Third, we examined the detail of the practice activities used by the players, and their impact on skill acquisition.

\section{Method}

\section{Participants}

104 chessplayers (101 males and 3 females) filled in a three-section questionnaire. They were recruited in several ways. First, the questionnaire was left visible at the reception desk in the Círculo de Ajedrez Torre Blanca, one of the most important chess clubs in Buenos Aires (Argentina). In addition, posters asking for volunteers were also put on the notice board of the club. Finally, GC went to several tournaments, both in the Círculo de Ajedrez Torre Blanca and other chess clubs in Buenos Aires, and distributed the questionnaires to the participating players. The participants included three grandmasters (mean age $=31$ years, $S D=3.5), 10$ international masters $(M=29.1, S D=10.7), 13 \mathrm{FIDE}^{1}$ masters $(M=27.1, S D=8.9)$, 39 untitled players with international rating $(M=30.2, S D=13.9)$, and 39 players without international rating $(M=33.2, S D=17.8)$. The mean age of the sample was 30.8 (range: from 10 to 78 years, median $=28$ years, $S D=14.5$ ). Since not all players 
had international rating, we used the national rating in order to measure chess skill in some analyses. The two ratings are closely related: in our sample, for the 65 players with both international and national ratings, the correlation between the two scales was .89. The range of the sample was 983 points (from 1490 to 2473), with a mean of 1991 and a standard deviation of 221. Since the Elo rating has a normal distribution with a theoretical SD of 200, our sample had a range of nearly 5 SD.

\section{Materials}

The questionnaire was divided into three sections. The first section (see appendix 1 for an English translation) consisted of questions about date of birth, age, profession, international rating, national rating, speed chess rating (rating of the Círculo de Ajedrez Torre Blanca) ${ }^{2}$ chess title, chess category, age at starting to play chess, age at starting to play chess seriously, age at joining a chess club (club age), presence of a coach $(0,1)$ at any time during the career, number of chess books owned, playing speed chess $(0,1)$, number of speed games played, and type of training (blindfold chess, reading games without seeing the board [henceforth, blindfold reading], use of chess databases, and use of chess programs). The second section contained a grid in which participants had to fill out the number of hours per week they spent studying chess alone at each age (henceforth, individual practice). They also had to fill out a second row with the number of hours per week they spent studying or practising with other chessplayers, including tournament games (henceforth, group practice) ${ }^{3}$ In both cases the participants were asked to estimate the mean number of hours per week they spent studying or practising each year. We estimated the number of hours studied per year by multiplying the figures reported by 52, and then we calculated the sum of the total hours spent with individual and group practice in their entire chess career. Not all players answered all questions, with the 
result that the number of data points varies across our measures. The third section contained the Edinburgh Handedness Inventory (Oldfield, 1971). As the results of the latter were already presented in a previous paper (Gobet \& Campitelli, 2007), we do not present these data here.

\section{Results}

We present the results according to the three issues developed in the introduction. First, we consider the results related to the importance of practice in achieving high levels of expertise in cognitive abilities. Second, we expound the results related to inter-individual variability in performance. Third, we discuss data related to the relative role of different types of practice.

\section{The Role of Practice}

We performed correlations between national rating and the total cumulative number of hours of individual practice on the one hand, and of group practice on the other hand. The correlation between current national rating and log cumulative individual practice was .42 ( $p<.0001$; calculated with 90 participants), and the correlation between current national rating and log cumulative group practice was .54 ( $p<.0001$; calculated with 89 participants $){ }^{4}$ These statistically significant correlations between the current skill level and two different measures of practice show that the amount of previous practice has a very important role in the current skill level.

Related interesting research questions include: How many hours per week do the players spend practising, on average? Is there a difference between the stronger players and the weaker players? And, do the players carry out more group practice or individual practice? In order to investigate these issues, we performed a $2 \times 3$ ANOVA with type of practice (group and individual) as a within-subjects independent variable, 
chess level (masters, experts, intermediates) as a between-subjects independent variable, and hours of practice per week as dependent variable. The masters were 17 players with one of the FIDE titles (that is, grandmasters, international masters, and FIDE masters); the experts were 35 players with international rating but without title; and the intermediate players were 31 players without international rating.

In order to estimate the mean hours of practice per week, we followed two procedures and we report both results. In the first one, we used a range from 4 years of age until the current age of the players. In the second one, the first data point was when the players reported starting playing chess. The first procedure takes age into account, while the second does not. The two procedures shed a slightly different light on the role of practice.

The results were similar for both measures. For the first procedure (i.e., calculation from 4 years of age), there was a main effect of type of practice, $F(1,80)$ $=27.54, p<.001$, a main effect of chess level, $F(2,80)=17.40, p<.001$, and a marginally significant interaction type of practice $\mathrm{x}$ chess level, $F(2,80)=3.07, p=$ .052. For the second procedure (i.e., calculation since starting playing age) we found a main effect of type of practice, $F(1,80)=19.71, p<.001$, a main effect of chess level, $F(2,80)=6.76, p<.005$, and a non-significant interaction, $F(2,80)=1.00$, ns. As expected, stronger players practice more hours per week than weaker players. The interesting result is that in the three chess levels group practice is more important than individual practice.

It can be argued that the measures used so far-cumulative practice until the present and mean hours of practice until the present—are inflated: some players may have acquired their current skill level some years ago, and therefore the number of hours beyond this point in time should not be counted. 


\section{INSERT FIGURE 1 ABOUT HERE}

\section{INSERT FIGURE 2 ABOUT HERE}

In order to address this possibility, we show in Figures 1 and 2 the number of hours of group and individual practice per week as a function of age and chess level. The data point at each age indicates the mean hours of practice per week in each group. The ages before the players started practising were coded as zero hours of practice. The ages older than the players' current age were not included in the calculation of the mean (i.e., at older ages, the means were calculated with fewer players than at younger ages).

It can be observed in the figures that the amount of individual and group practice is different in the three groups. It is also apparent that, overall, the amount of group practice is greater than that of individual practice. More importantly, both figures allow us to visualise that the differences in time spent practising among groups started early on, and that these differences are also present in the range of 13 to 25 years of age. Interestingly, around the 30 's experts play (i.e., practice in group) a similar number of hours per week as masters. It has been argued elsewhere (Dextreit \& Engel, 1981) that non-professional players show interest and commitment to the game of chess until the late teens, when the amount of time devoted to chess peaks. After this, players often start work, attend university, and/or get married, which dramatically reduces the time spent playing and studying chess. In the mid-30s, when family and work issues are more stable, players return to the game and play more frequently. 


\section{INSERT TABLE 1 ABOUT HERE}

With respect to the data of experts and intermediates presented in Figure 1 and 2, this hypothesis predicts a cubic function, with increase up to about 18 years old where there should be a peak, then decrease to a local minimum, and then increase again. We tested this hypothesis with linear $(y=a+b x)$, quadratic $\left(y=a+b x+c x^{2}\right)$ and cubic $\left(y=a+b x+c x^{2}+d x^{3}\right)$ regression analyses predicting hours of practice as a function of age. Table 1 shows that, as predicted, the data of experts and intermediates were fitted better by a cubic function than with a linear or quadratic function. In particular, with the intermediates the cubic function explains at least an additional $41 \%$ of the variance compared to the linear and quadratic functions. With the masters, who were expected to be professionals, the cubic function does not improve on the quadratic with individual practice, although, somewhat surprisingly, it does with group practice.

\section{INSERT FIGURE 3 ABOUT HERE}

INSERT FIGURE 4 ABOUT HERE

It is a common practice in the deliberate practice literature to plot the cumulative number of hours of practice as a function of years of practice since the participants began to seriously apply themselves to a domain (e.g., Charness et al., 2005; Ericsson et al., 1993). Figure 3 shows the estimated number of cumulative group practice as a function of years of studying seriously, and Figure 4 shows the estimated number of cumulative individual practice as a function of years of studying seriously. We consider the year at which the participants reported studying chess 
seriously as the first year of serious practice and the figures depict the estimated number of hours of practice in the first ten years of serious practice. These figures are in agreement with the previous ones in that the three groups differ in the number of hours of cumulative group and individual practice. They also show that the differences in group practice (Figure 3) arise earlier that those in individual practice (Figure 4). ${ }^{5}$ Not all the players in our sample achieved ten years of serious practice (either because they became serious at chess late or because they were too young at the point of measurement); therefore, the average hours of practice for each year was calculated with a different number of players. This explains why in Figure 4 the estimation of average cumulative number of hours of individual practice in intermediate players at 9 and 10 years of serious practice is lower than that of 6 to 8 years of serious practice.

\section{Inter-Individual Variability}

Addressing the second issue, that of inter-individual variability, requires correlating a measure of amount of practice with a measure of performance variability. To do so, we ranked the players of our sample according to the amount of cumulative individual practice, and then divided the sample into 9 groups of 10 players. Thus, groups were homogeneous with respect to players' amount of practice, with average practice increasing from group 1 to group 9. For each group, we calculated the mean and standard deviation for national rating (see Figure 5). Then, we obtained the correlation of the mean national rating of the groups with their mean number of hours of individual practice. Also, we calculated the correlation between the standard deviation of national rating and the mean number of hours of individual practice. We divided the sample into 9 groups in order to have enough data points for 
the correlation analysis and enough subjects within each group for the average ratings and standard deviations of rating to be calculated reliably.

In Figure 5, the blip occurring in group 6 with the standard deviation of national rating is due to an outlier, which was removed in all the following analyses. (The pattern of correlations and significances is the same when this outlier is included in the analyses.) There was a significant positive correlation between mean national rating and mean number of hours of individual practice, $r(7)=.79, p<.02$, but we did not find any significant correlation between standard deviation of national rating and mean hours of individual practice, $r(7)=.38, n s$.

\section{INSERT FIGURE 5 ABOUT HERE}

We followed the same procedure with group practice (see Figure 6). We found a significant positive correlation between mean national rating and mean number of hours of group practice, $r(7)=.94, p<.001$, and we also found a significant negative correlation between standard deviation of national rating and mean hours of group practice, $r(7)=-.82, p<.01$.

\section{INSERT FIGURE 6 ABOUT HERE}

Given that age is positively correlated with amount of practice in this sample (see Gobet \& Campitelli, 2007, p. 164), it is possible that the significant correlations presented in the previous analyses are accounted for by this variable. In order to investigate this issue we calculated partial correlations, controlling for the mean age of each group. There was no significant partial correlation between mean national 
rating and mean number of hours of individual practice, $r(6)=.61$, ns., nor between standard deviation of national rating and mean hours of individual practice, $r(6)=.30$, ns. However, there was a significant positive partial correlation between mean national rating and mean number of hours of group practice, $r(6)=.89, p<.005$, and a significant negative partial correlation between standard deviation of national rating and mean hours of group practice, $r(6)=-.87, p<.005$. Given the relatively low power of these analyses, some of the medium-sized but non-significant correlations should be interpreted with caution.

Until now, we have used current chess level (measured by current national rating) as dependent variable. An interesting additional question is how ratings change as a function of yearly practice. Given that we did not have complete archives for the national rating, we used archives of international rating. Using international rating had the disadvantage that not all players were included, because the entry requirements are higher than those of national rating. Therefore, only a sub-sample could be included (17 masters and 35 experts); in addition, information is lacking about what happened at young ages or during the first years of serious practice. Nonetheless, our data are useful to show different trends in performance change in masters and experts from the time they achieved the level of experts.

\section{INSERT FIGURE 7 ABOUT HERE}

\section{INSERT FIGURE 8 ABOUT HERE}

Figures 7 and 8 show the international rating for the current masters and experts, as a function of years of serious practice and age respectively. Figure 7 was constructed as follows. First, we determined the starting point for each player; for that 
purpose, we used the year in which the players reported they started playing seriously. Therefore "age" in this figure does not matter. For example, a player who reported the age of 13 would have 1 year of serious playing at the age of 14,2 years of serious playing at the age of 15 , and so forth. Another player that started playing seriously at the age of 6 would have 1 year of serious playing at the age of 7 , and 8 years of serious playing at the age of 14 . Then, we calculated the average international rating of both groups at each number of years of serious playing. The number of players at each of the $\mathrm{x}$-axis values changes. For example, there were many players younger than 20 years, so they could not possibly have data for 20 years of serious playing. Note also that we started the analysis at 3 years of serious playing because there was a negligible number of players with international rating after 1 or 2 years of serious playing.

We performed a regression analysis to predict international rating in masters and experts as a function of the number of years of practising chess seriously (the range of years of serious practice was 3 to 20). The correlation between international rating and the number of years of serious practice was significant both for masters $(r(16)=.95, p<.0001)$ and experts $(r(16)=.40, p=.05)$. The regression analyses showed the following results:

international rating of masters $=2257+7.0 *$ years of serious practice; international rating of experts $=2174+1.03 *$ years of serious practice.

These results show that, after three years of practice, masters have on average 83 international rating points more than experts (i.e., 2257 vs. 2174). Moreover, from this point masters increase at the rate of 7 international rating points per year of serious practice, whereas experts only increase at the rate of 1 Elo point per year of 
serious practice. The difference between the two slopes was statistically significant: Hotelling's $t(15)=5.5, p<.01$.

For Figure 8, we calculated the average international rating of players at each age for both groups. We started the analysis at the age of 14 because there were too few players with international rating before this age. We performed the same analysis as above with age as a predictor variable (the age range was from 14 to 33). The correlation between international rating and age was significant with the masters, $r(18)=.85, p<.0001)$, and non-significant with the experts, $r(18)=.02, n s$. The regression analyses provided the following equations: international rating of masters $=2169+7.2 *$ age; international rating of experts $=2189+0.05 *$ age

This result is similar to the previous one for the masters but not for the experts. The experts seem to benefit somehow from the first years of serious practice and only if they start before the age of 14 ; after this age they do not seem to improve at all. The difference between the two slopes was statistically significant: Hotelling's $t(17)=4.5$, $p<.01$

The analyses of the data presented in Figures 7 and 8 should be taken with caution. The means at each value of the $\mathrm{x}$-axes were calculated only with the players that had an international rating. It was not appropriate to follow the same procedure as with Figures 1 and 2 (i.e., to calculate the mean value including the players with 0 hours of practice) because lack of international rating is not lack of chess skill. Hence, the absolute values of international rating at each data point do not reflect the true chess skill of the group perfectly. On the other hand, the differences between the slopes show a reliable pattern: experts increase their skill level very little with the pass of time, whereas masters keep increasing theirs. 


\section{INSERT FIGURE 9 ABOUT HERE}

\section{INSERT FIGURE 10 ABOUT HERE}

We performed a different analysis with the same data in order to show that the pattern is reliable. We calculated the percentage of players with international rating and the percentage of players with more than 2200 Elo points at each year of serious practice (see Figure 9) and age (see Figure 10). The data show a clear difference between experts and masters.

\section{Differential Role of Types of Practice}

We have been analysing two types of practice: group practice and individual practice. However, within these two categories there are different specific activities, and we enquired about them in our questionnaire. Variables corresponding to group practice were: coaching, blindfold chess, playing speed chess and log number of speed chess games. Individual practice was represented by the following activities: blindfold reading, use of databases, use of chess programs, and log number of books. We followed Charness et al.'s (1996) and Charness et al.'s (2005) assumption that if chessplayers have books they would read them, or at least some of them. Therefore, the quantity of books owned could be a predictor of hours spent reading books.

The percentages of players who reported using these activities were as follows: playing speed chess, $83.6 \%$; coaching $(0,1), 80.5 \%$; use of databases, $67.3 \%$; use of programs, $66.3 \%$; blindfold reading of games, 55.7\%; and blindfold chess, $23 \%$. We assessed the zero-order correlations between these practice activities and skill. With national rating used as dependent variable, the correlations were .44 for $\log$ 
number of books, .35 for the presence of coaching $(0,1), .32$ for the use of databases $(0,1), .27$ for playing speed chess $(0,1)$, and .27 for log speed games (all $p<.05)$. There were no significant correlations between skill and blindfold chess, blindfold reading of games, use of chess programs.

The activities that are most practised by the players in this sample—-speed games and coaching $(0,1)$-were correlated with skill, and thus seem to be useful as well. Use of databases and computer programs are activities that were performed by the same number of players, but the mean national rating of players using databases was higher than that of players using programs. Playing blindfold games was not an activity performed by many players and it did not have a high correlation with skill level either. With speed chess rating used as dependent variable, the correlations were .38 for $\log$ number of books, and .35 for coaching (both $p<.05$ ). There were no significant correlations with the other variables.

We entered the eight variables corresponding to either group practice or individual practice into a stepwise regression analysis, which removed all variables except Log number of books, Presence of coach $(0,1)$, and Log number of speed games. A multiple regression with these three independent variables showed that they all made a significant contribution (see Table 2). As Charness et al.'s (2005) showed that age was a moderator of the link between practice activities and skill level, we carried out additional analyses with these three independent variables, splitting our sample in players below 40 years of age and above (or equal) 40 years of age. The results, shown in Tables 3 and 4, showed that with younger players, only Log number of books was a significant predictor of skill, while, with older players, Log number of books and Log number of speed games were predictors, the latter only marginally so. 
Taking into account the activities measured in the questionnaire, we can conclude that reading (as inferred by the number of books), an individual activity, is the most important predictor of chess skill. On the other hand, coaching and log speed games, two group activities, were also significant predictors of chess skill, although their importance was moderated by age.

\section{INSERT TABLES 2, 3, and 4 ABOUT HERE}

\section{Discussion}

In the introduction we mentioned three issues: (a) to what extent is the amount of practice important to achieving high levels of expertise? (b) does everybody benefit from practice in the same way? and (c) what types of chess activities are most useful, and in what order should they be practised? To address these three issues, we considered both individual and group practice. We first discuss how our data stand regarding these issues. Then, we will address the topics of generalisation and transfer. Finally, we will consider the implications of our study for learning sciences in general.

Before tackling these issues, we address the question of the reliability of the questionnaire used in this study. It has been argued that individuals might not reliably report their behaviour in the past (e.g., Davids, 2000; Starkes, Weir, \& Young, 2003). However, previous research has shown that this kind of questionnaire correlates fairly well with independent measures (Ericsson et al., 1993). In addition, this methodology produces results that are replicable. We used the same method as two previous studies on chess (Charness, Krampe \& Mayr, 1996; Charness et al., 2005), and, for example, one key result — the correlation between cumulative hours of individual practice and 
skill level — is fairly similar in the three studies, considering the fact that the players participating in these studies come from three continents. We found a correlation of .42, Charness et al. (1996) found a correlation of .60, and Charness et al. (2005) found a correlation of .54 for the enlarged sample from their 1996 study, and .48 for a new sample.

Regarding the role of practice in the acquisition of high-level cognitive skills, our data partly support Ericsson et al.'s (1993) framework of deliberate practice but are against an extreme view of the role of practice (e.g., Howe, Davidson, \& Sloboda, 1998). Moreover, our data are against an extreme view of the role of talent in the acquisition of high-cognitive skills (e.g., Galton, 1869/1979). We found a significant correlation between individual practice and national rating and also a significant correlation between group practice and national rating. This result is also consistent with previous similar studies in music (Ericsson et al., 1993), chess (Charness et al., 1996; Charness et al., 2005) and sports (Janelle \& Hillman, 2003). On the other hand, none of these studies showed a correlation that accounts for all or even most of the variability in skill level. There are several reasons why not all the variability is explained by the number of hours of practice: measurement error, lack of sensitivity of the method used, differences in quality of the activities performed (e.g., some players may have had better coaches than others), age at which players started playing chess or studying seriously, or non-chess related factors.

In a separate paper (Gobet \& Campitelli, 2007), we explored other factors not related to practice that may influence skill. We showed that a non-chess related factor, handedness, differentiated chess players from the general population (i.e., there were more non-right handed persons in a chess sample than in a non-chess sample). We also found that the age at which players started playing seriously or enrolled in a 
chess club was an important factor (i.e., there is a critical or sensitive period to start practising chess seriously in order to achieve high levels of skill). This finding was strengthened by the analyses presented in the current paper.

The novelty of the present article is that we present longitudinal data, which affords the possibility of showing increases in rating and in amount of practice as a function of age or as a function of years of serious practice. This new analysis shows a difference in the number of hours of chess practice at early ages between masters, experts and intermediate players (see Figures 1 and 2). Masters also showed an advantage over experts in chess rating after only 3 years of serious practice (see Figure 7), although there was no difference in amount of practice between masters and experts after 3 years of serious practice (see Figures 3 and 4). This is a clear indication that the first 3 years of serious practice at early ages are much more profitable than the first 3 years of serious practice at later ages. Moreover, the present data indicate that there was a considerable amount of dedication to chess before the period players reported becoming serious about chess (between 10 and 12 years old in masters and around 14 years old in experts; see Gobet \& Campitelli, 2007, p. 163) and that differences between masters and the rest of the players were already noticeable by then (see Figures 1 and 2). This indicates that recreational exposure to chess at early ages is also important, in contradiction to the deliberate practice framework. Therefore, an extreme view that considers practice as a necessary and sufficient condition to acquire high levels of expertise is not supported by our data. These new findings highlight the advantages of using longitudinal data.

In order to address the second issue, we analysed our data from a different perspective. Thorndike (1908) and Ackerman (1987) argued that with increased practice the inter-individual variability in performance should diminish if the main 
factor in mastering the task is practice. Moreover, the inter-individual variability in performance should increase if the main factor in mastering the task is an innate ability. Using national rating as a measure of performance and separating groups according to their cumulative number of hours of practice, we found a significant negative correlation between the number of hours of group practice and the standard deviation of national rating. However, we did not find any correlation with individual practice.

Following Thorndike's (1908) and Ackerman's (1987) rationale, the decrease in performance variability with increasing group practice (see Figure 6) shows that practice is an important factor in the acquisition of high-level performance in chess. On the other hand, individual practice did not show a significant negative correlation. This suggests that no matter how much individual practice players engage in, the initial differences in performance would be maintained, but the more they engage in group practice, the less the differences in rating between players should be. The partial correlation analyses showed that although age accounted for a part of the correlations, the pattern remained the same: high negative correlation between standard deviation of chess rating and group practice (marginally significant), and low negative correlation between standard deviation of chess rating and individual practice (non-significant).

These results suggest the following hypotheses. First, group practice is an essential aspect of the acquisition of a high performance in a high-level cognitive skill such as chess. However, it can only be considered as a necessary, but not sufficient, condition because the variability in performance diminishes with group practice, but does not disappear. Second, individual practice is also a necessary, but not sufficient, condition for acquiring expert performance in chess. Individual practice is the type of 
activity needed to acquire a vast database of chess knowledge. The more individual practice, the higher the chess level. However, differences in individual practice alone cannot explain the inter-individual variability in performance that is observed early on, when players have little time of practice behind them (cf. Figures 7 and 8). Thus, third, group practice plus individual practice plus factors unrelated to practice are the necessary and sufficient conditions to achieve high-level performance in cognitive skills such as chess. What are these factors? As explained above, in a separate paper (Gobet \& Campitelli, 2007), we showed that the age at which players start to play seriously, controlling for number of hours of practice, is a good predictor of chess skill and that an innate factor (i.e., handedness) differentiated chess players from nonchess players. Therefore, we suggest that large amounts of individual and group practice, starting serious practice as early as possible, and some innate factors (perhaps the ones responsible for determining handedness) are important factors for acquiring expert performance.

The third issue we tackled in our study was that of the types of activities that are useful for acquiring high-level cognitive skills. We examined this issue in two different ways. First, when considering the role of practice, we investigated the differential roles of individual and group practice and, second, we enquired about more specific activities. This is an important issue because, although we agree with Ericsson et al.'s (1993) thesis that deliberate practice is a crucial factor for the achievement of expert performance, we consider that their description of deliberate practice in chess is simplistic. For example, they explicitly rule out tournament games as part of deliberate practice. However, Charness et al. (1996, p. 75) presented data which showed that active participation in chess tournaments was considered the most relevant activity by chess players. Given that deliberate practice is the intentional 
implementation of activities aimed at improving performance, it is reasonable to assume that experts are aware of these activities and the extent to which they are beneficial to them. Thus, chess players' and in particular chess experts' reports that playing competitive games is an important activity cannot be dismissed readily, as has sometimes be done in the literature. Moreover, the development of chess theory and computer technology changed the way chess players prepare for their games (see Gobet et al., 2002). Chess players not only try to predict the best move in chess games and then receive feedback, as proposed by Ericsson et al. (1993), but they also memorize typical manoeuvres and opening variations with the aid of either books or electronic databases, they investigate opening positions to find novelties to surprise their opponents, and they play tournament or training games (against other players physically present, on the internet, or against computer programs). Thus, becoming a master calls for the acquisition of vast amounts of knowledge, which requires training activities that go beyond the type of repetitive and feedback-informed activities typically emphasised in the deliberate practice literature.

When dealing with the first analysis, we found a higher correlation between group practice and national rating than that between individual practice and national rating. Moreover, Figures 3 and 4 clearly show that the cumulative number of hours of group practice is higher than that of individual practice from very early ages. These results suggest that relevant activities that involve social interaction are more important than previously thought. For example, Charness et al. (1996) showed that individual practice was a better predictor of chess skill than group practice. How can we explain the difference between Charness et al. $(1996,2005)$ and the present study? Although we used a national measure of chess skill, which is highly correlated with the international rating (therefore, in this respect, our results are generalisable to the 
whole chess community), there are other factors that may be specific of our sample. For example, the former studies were carried out with participants of Russia, Germany, Canada and United States, whereas our study was carried out with Argentine players. There may be cultural differences in the way Argentine players approach chess in comparison to European and American players. Another reason that may explain this difference is the wording of the questions. Charness et al.'s (2005) question about group practice is only restricted to serious competition, whereas our question about group practice included both serious competition and study with other players.

Another interesting pattern is that individual practice drastically diminishes at the age of 18 in experts and intermediate players (see Figure 2). This is the age at which most people in Buenos Aires either start university or start working; therefore, these data may be showing that only masters that are having good results keep practising at home, whereas experts and intermediates only continue playing chess for fun at their leisure time.

Regarding the specific activities, we found that reading books, playing speed chess, using databases, and having a coach are the most important ones inasmuch as they showed the highest correlations with national rating, although the impact of these activities on rating was moderated by age. This result suggests that the acquisition of high levels of chess skill requires both individual practice (i.e., reading books and studying with databases of chess games) and group practice (playing games and receiving chess classes or coaching). These findings can be explained in terms of a general theory of expertise: the template theory (Gobet \& Simon, 1996a). We first briefly explain the theory and then we relate these findings with the theory. 
An extension of Chase and Simon's (1973) chunking theory, Gobet and Simon's (1996a) template theory of expertise has received strong support from studies in perception (Chase \& Simon, 1973; De Groot \& Gobet, 1996; Ferrari, Didierjean, \& Marmèche, 2006), memory (Chase \& Simon, 1973; Gobet \& Simon, 1996, 2000), imagery (Saariluoma, 1991; Campitelli \& Gobet, 2005) and problem solving (Gobet, 1998b; Campitelli \& Gobet, 2004). The support for the mechanisms underpinning template theory comes not only from chess but also from different fields such as language acquisition (Freudenthal, Pine, \& Gobet, 2006), computer programming (Gobet, Lane, Croker, Cheng, Jones, Oliver, \& Pine, 2001), and physics (Lane, Cheng, \& Gobet, 2000).

In short, template theory states that high-level cognitive skills are acquired by learning numerous domain-specific patterns that are stored in long-term memory. A distinction is made between "chunks," which are fixed perceptual patterns, and "templates," which are patterns made both from fixed and variable information. By relevant interaction with the environment, the patterns are linked together forming larger patterns. These patterns are not only static configurations but are also linked with possible actions. Another aspect of the template theory is that receiving feedback from the environment changes the links between the patterns and the actions linked to them. Finally, the generation of a vast knowledge base is not acquired rapidly but requires several years of practice. The template theory (Gobet \& Simon, 1996) states that any high-level cognitive skill is acquired by the same simple mechanisms. The difference between different domains is the content of the learned patterns, which is a function of the type of interaction with the environment. A discussion of the mechanisms required to acquire high-level cognitive skills is beyond the scope of this article; suffice it to point out here that the mechanisms were implemented in computer 
models that simulated human data in detail (Freudenthal et al., 2006; Gobet \& Simon, 2000).

Within the framework of the template theory, playing numerous games facilitates the acquisition of a large knowledge base of domain specific patterns in long-term memory. (Note that playing rapid chess allows for the playing of many more games than normal chess in the same amount of time.) However, it is necessary to complement playing games with reading books, receiving formal coaching, and using chess databases. Without the learning of proper actions to carry out in a given situation, the large database of domain-specific patterns held in long-term memory (chunks and templates) would be useless: a specific situation would be recognized, but the player would not have knowledge as to what to do given this situation. Activities such as coaching, studying databases with games of grandmasters or reading books with grandmaster's comments make it possible to learn specific chess methods and sequences of moves and to link this procedural knowledge to perceptual patterns, thus giving quality to the knowledge base. Playing rapid games may also contribute to an ability important in the development of chess skill: the aptitude for making decisions rapidly under time pressure, with only a minimal exploration of the search tree and thus far less information than could be obtained after several minutes of deliberation. This is partly made possible by the presence of chunks and templates, which speed up the rate at which strong players can generate moves as they can rely on automatic, pattern-recognition based processing rather than using slower heuristics (Gobet, 1997).

Since the results reported in this article are consistent with a general theory of expertise we consider that they can be generalised to other high-level cognitive domains. However, we are negative about the possibility of transferring skills from 
chess to other domains, and we do not recommend studying chess in order to improve performance in other domains. Although there are strong claims in this respect, we have showed elsewhere that most studies that claimed transfer from chess to other cognitive skills had severe methodological problems (see Gobet \& Campitelli, 2006, for a review of research into chess and education). The explanation for the lack of transfer is simple: our cognitive system operates with general mechanisms; what differs is the type of information that we acquire from the environment. Acquiring a vast knowledge base in one domain requires investing time and effort, and therefore leaves less time to devote to the domain to which one wants to transfer skills. We would predict transfer between domains that have similar environments but not between domains that deal with different environmental information. For example, in our sample, the correlation between national rating and speed chess rating is high (i.e., $.83)$. Both skills share the same environment and follow the same rules, the only difference being that the national rating measures chess performance in games lasting 4 hours on average and the speed chess rating measures performance in games lasting 10 minutes on average.

Finally, we draw conclusions for learning and teaching. Our data support constructivist methods where the activity of the learner is emphasised and oppose traditional educational methods where the student's role is mostly passive. This study showed that chess masters start engaging in group practice early on and to a larger extent than experts and intermediate players. For example, at the age of 8 the average number of cumulative hours of individual practice is 202,51 , and 5 in masters, experts and intermediates, respectively; by contrast, the average number of cumulative hours of group practice at the same age is higher in all the groups (547, 279 and 82, respectively). Given the correlational nature of our analysis, we cannot 
decide whether the masters of our study practised in group more than the experts and intermediates because they were winning more or that practising more led to improved performance. In any case, from a learning standpoint our data suggest that it is advisable to start participating in group activities from the beginning. Children should have a strong interaction with the environment by playing against peers, receiving qualified advice from a teacher or coach as a complement of reading books individually. Moreover, the use of new technologies (in our case chess databases but not chess playing programs) favours the acquisition of high-level cognitive skills (see also Gobet, Campitelli \& Waters, 2002).

An important finding of this article is that practice seems to be more profitable at early ages than at older ages. This can be explained by the importance that the template theory gives to the order in which knowledge is acquired (see Gobet, 2005). Younger children tend to pay attention to concrete things; therefore it is likely that they will prefer the perceptual configuration of chess pieces rather than conceptual knowledge. Gobet (2005) argued that conceptual schemata (or templates) are better acquired on the basis of perceptual chunks, because these chunks provide a cue that would improve the efficiency of memory retrieval in the future. It is probable that older teenagers, who have been already exposed to logical thinking at school, pay relatively more attention to conceptual aspects of chess games before acquiring the domain-specific perceptual chunks. As suggested by Gobet (2005) this would impact in the speed of information retrieval in future chess games.

To conclude, our longitudinal data raise important questions with respect to the deliberate practice framework. Contrary to its assumptions, practice is more beneficial at early than later ages; group practice is more important than individual practice; in spite of the absence of difference in amount of serious practice between 
masters and experts in the first three years, the former had higher ratings than the latter; and the experts did not improve much after three years in spite of considerable amounts of deliberate practice. Together, these results raise serious doubts as to whether practice is sufficient for reaching high levels of expertise. Similarly, our data do not support traditional educational methods of acquiring a vast knowledge base by long hours of isolation and little social interaction. Rather, reading books is still advisable only if it is complemented with rich interaction with the environment. In this way, the knowledge base — the essential aspect of high-level skill acquisitionwould not only be sizeable but it would also be of high quality. 


\section{References}

Ackerman, P. L. (1987). Individual differences in skill learning: An integration of psychometric and information processing perspectives. Psychological Bulletin, $102,3-27$.

Anderson, J. R., Reder, L. M., \& Simon, H. A. (2000, Summer). Applications and misapplications of cognitive psychology to mathematics education. Texas Education Review.

Baxter, G. P., \& Glaser, R. (1998). Investigating the cognitive complexity of science assessments. Educational measurements: Issues and practices, 17, 37-45.

Campitelli, G., \& Gobet, F. (2004). Adaptive expert decision making: Skilled chess players search more and deeper. Journal of the International Computer Games Association, 27, 209-216.

Campitelli, G., \& Gobet, F. The mind's eye in blindfold chess. European Journal of Cognitive Psychology, 17, 23-45.

Charness, N. (1981). Aging and skilled problem solving. Journal of Experimental Psychology: General, 110, 21-38.

Charness, N., Krampe, R. Th., \& Mayr, U. (1996). The role of practice and coaching in entrepreneurial skill domains: An international comparison of life-span chess skill acquisition. In K. A. Ericsson (Ed.), The road to excellence (pp. 51-80). Mahwah, NJ: Erlbaum.

Charness, N., Reingold, E. M., Pomplun, M., \& Stampe, D. M. (2001). The perceptual aspect of skilled performance in chess: Evidence from eye movements. Memory \& Cognition, 29, 1146-1152. 
Charness, N., Tuffiash, M., Krampe, R., Reingold, E., \& Vasyukova, E. (2005). The role of deliberate practice in chess expertise. Applied Cognitive Psychology, 19, $151-165$.

Chase, W. G., \& Simon, H. A. (1973). The mind's eye in chess. In W. G. Chase (Ed.), Visual information processing. New York: Academic Press.

Cooke, N. J., Atlas, R. S., Lane, D. M., \& Berger, R. C. (1993). Role of high-level knowledge in memory for chess positions. American Journal of Psychology, $106,321-351$.

Davids, K. (2000). Skill acquisition and the theory of deliberate practice: It ain't what you do it's the way that you do it! International Journal of Sport Psychology, $31,461-466$.

De Groot, A. D., \& Gobet, F. (1996). Perception and memory in chess. Assen: Van Gorcum.

Dextreit, J., \& Engel, N. (1981). Jeu d'échecs et sciences humaines [Chess and human sciences]. Paris: Payot.

Elo, A. E. (1978). The rating of chessplayers. Past and present. New York: Arco.

Ericsson, K. A., Krampe, R. Th., \& Tesch-Romer, C. (1993). The role of deliberate practice in the acquisition of expert performance. Psychological Review, 100, 363-406.

Ferrari, V., Didierjean, A., \& Marmèche, E. (2006). Dynamic perception in chess. The Quarterly Journal of Experimental Psychology, 59, 397-410.

Freudenthal, D., Pine, J. M., \& Gobet, F. (2006). Modelling the development of children's use of optional infinitives in English and Dutch using MOSAIC. Cognitive Science, 30, 277-310. 
Galton, F. (1979). Hereditary genius. An inquiry into its laws and consequences. London: Julian Friedman. (Originally published in 1869).

Gobet, F. (1997). A pattern-recognition theory of search in expert problem solving. Thinking \& Reasoning, 3, 291-313.

Gobet, F. (1998a). Chess players' thinking revisited. Swiss Journal of Psychology, 57, $18-32$.

Gobet, F. (1998b). Expert memory: A comparison of four theories. Cognition, 66, $115-152$.

Gobet, F. (2005). Chunking models of expertise: Implications for education. Applied Cognitive Psychology, 19, 183-204.

Gobet, F., \& Campitelli, G. (2007). The role of domain-specific practice, handedness and starting age in chess. Developmental Psychology, 43, 159-172.

Gobet, F., \& Campitelli, G. (2006). Educational benefits of chess instruction: A critical review. In T. Redman (Ed), Chess and education: Selected essays from the Koltanowski conference (pp. 124-143). Dallas, TX: Chess Program at the University of Texas at Dallas.

Gobet, F., Campitelli. G., \& Waters, A. J. (2002). Rise of human intelligence: Comments on Howard (1999). Intelligence, 30, 303-311.

Gobet, F., de Voogt, A. J., \& Retschitzki, J. (2004). Moves in mind: The psychology of board games. Hove, UK: Psychology Press.

Gobet, F., Lane, P. C. R., Croker, S., Cheng, P. C-H., Jones, G., Oliver, I. \& Pine, J. M. (2001). Chunking mechanisms in human learning. Trends in Cognitive Sciences, 5, 236-243.

Gobet, F., \& Simon, H. A. (1996 a). Templates in chess memory: A mechanism for recalling several boards. Cognitive Psychology, 31, 1-40. 
Gobet, F., \& Simon, H. A. (1996 b). The roles of recognition processes and lookahead search in time-constrained expert problem solving: Evidence from grandmaster-level chess. Psychological Science, 7, 52-55.

Gobet, F., \& Simon, H. A. (2000). Five seconds or sixty? Presentation time in expert memory. Cognitive Science, 24, 651-682.

Gobet, F., \& Wood, D. J. (1999). Expertise models of learning and computer-based tutoring. Computers and Education, 33, 189-207.

Hatano, G., \& Inagaki, K. (1986). Two courses of expertise. In H. Stevenson, H. Azuma \& K. Hakuta (Eds.), Child development and education in Japan (pp. 262-272). New York: Freeman.

Howe, M. J. A., Davidson, J. W., \& Sloboda, J. A. (1998). Innate talents: Reality or myth? Behavioral and Brain Sciences, 21, 399-442.

Janelle, C. M., \& Hillman, C. H. (2003). Expert performance in sport: Current perspectives and critical issues. In J. L. Starkes \& K. A. Ericsson (Eds.), Expert performance in sports: Advances in research on sport expertise (pp. 19-45). Champaign, IL: Human Kinetics.

Lane, P. C. R., Cheng, P. C. H., \& Gobet, F. (2000). CHREST+: Investigating how humans learn to solve problems using diagrams. AISB Quarterly, 103, 24-30.

Oldfield, R. C. (1971). The assessment and analysis of handedness: The Edinburgh Inventory. Neuropsychologia, 9, 97-113.

Saariluoma, P. (1991). Aspects of skilled imagery in blindfold chess. Acta Psychologica, 77, 65-89.

Simon, H. A. (1980). Problem solving and education. In D. Tuma \& F. Reif (Eds.), Problem solving and education (pp. 81-96). Hillsdale, NJ: Erlbaum. 
Starkes, J. L., Weir, P. L., \& Young, B. W. (2003). Retaining expertise. In J. L. Starkes \& K. A. Ericsson (Eds.), Expert performance in sports: Advances in research on sport expertise (pp. 252-270). Champaign, IL: Human Kinetics.

Thorndike, E. L. (1908). The effect of practice in the case of purely intellectual function. American Journal of Psychology, 19, 374-384.

Watson, J. B. (1924). Behaviorism. New York: People's Institute Publishing Company. 


\section{APPENDIX 1: CHESS QUESTIONNAIRE}

\section{$\underline{\text { (English translation from Spanish) }}$}

Answer all the questions, please. Leave a blank space only if you do not possess the ratings requested. If you do not know your rating/ratings, you can ask the secretary for it/them. Alternatively, you can write down your name to allow us to look up your ratings. Moreover, fill out the form of hours of study and practice in chess following the instructions. Thank you for your participation.

1) How old are you?

2) What is your profession?

3) What is your national Elo rating?

4) What is your speed chess rating?

5) What is your category?

6) What is your international Elo rating?

7) Do you have any title (GM, IM, FM)? Which one?

8) At what age did you learn how to play chess?

9) At what age did you start playing chess seriously?

10) How many hours per week (on average) have you studied alone during the current year?

11) How many hours per week (on average) have you studied or practised chess with other chess players (including tournament games) during the current year?

12) Have you ever joined a chess club?

If yes, at what age for the first time?

13) Have you ever received formal chess instruction from a chess coach?

Individual coaching: from (age) to (age)

Group coaching: from (age) to (age)

14) How many books do you have? (excluding chess journals)

15) Do you play blindfold chess?

16) Do you reproduce chess games from journals without using the chessboard?

17) Do you use any computer database to study chess?

18) Do you play games against chess software?

19) Do you play speed chess games?

How many per week? 
Table 1

Amount of Variance $\left(r^{2}\right)$ Explained by Linear, Quadratic, and Cubic Regressions, as a Function of Skill Level and Type of Practice.

\begin{tabular}{lllllll} 
& \multicolumn{2}{c}{ Linear } & Quadratic & \multicolumn{2}{c}{ Cubic } \\
\cline { 2 - 4 } & & & & & & \\
Skill & $\mathrm{r}^{2}$ & $\mathrm{~F}$ & $\mathrm{r}^{2}$ & $\mathrm{~F}$ & $\mathrm{r}^{2}$ & $\mathrm{~F}$ \\
\hline
\end{tabular}

Group practice

$\begin{array}{lcccccc}\text { Masters } & .25 & 10.6^{* *} & .59 & 22.0^{* * *} & .80 & 41.1 * * * \\ \text { Experts } & .41 & 22.0^{* * *} & .45 & 12.7^{* * *} & .78 & 35.7 * * * \\ \text { Intermediates } & .14 & 5.3^{*} & .19 & 3.7^{*} & .66 & 19.3 * * *\end{array}$

Individual practice

\begin{tabular}{lcccccc} 
Masters & .14 & $5.4^{*}$ & .83 & $75.7^{* * *}$ & .83 & $50.5^{* * * *}$ \\
Experts & .05 & 1.8 & .51 & $15.9^{* * *}$ & .63 & $17.0^{* * * *}$ \\
Intermediates & .09 & 3.2 & .15 & 2.6 & .56 & $12.8^{* * * *}$ \\
\hline
\end{tabular}

Note: The degrees of freedom are 32, 31, and 30 for the linear, quadratic, and cubic regression, respectively.

$* \mathrm{p}<.05 . * * \mathrm{p}<.01 . * * * \mathrm{p}<.001$. 
Table 2. Multiple regression predicting national rating using practice variables (entire sample).

\begin{tabular}{lcccccc}
\hline Variable & B & SE & Beta & t & $\mathrm{p}$ & $95 \% \mathrm{Cl}$ \\
\hline Constant & 1597.0 & 65.6 & & $24.3<.001$ & $1466.7,1727.4$ \\
Log number of books & 158.8 & 34.7 & .403 & $4.58<.001$ & $89.9,227.8$ \\
Presence of coach $(0,1)$ & 136.4 & 52.4 & .233 & $2.60<.02$ & $32.4,240.4$ \\
Log number of speed games & 62.0 & 29.2 & .190 & $2.13<.05$ & $4.1,120.0$
\end{tabular}

Note. $R=.557, R^{2}=.310$, Adjusted $R^{2}=.288, F(3,91)=13.64, p<.001$. 
Table 3. Multiple regression predicting national rating using practice variables (players younger than 40 years).

\begin{tabular}{lrrrrrr}
\hline Variable & B & SE & Beta & t & $p$ & $95 \% \mathrm{Cl}$ \\
\hline Constant & 1646.8 & 97.3 & & $16.9<.001$ & $1452.6,1840.9$ \\
Log number of books & 165.2 & 42.2 & .421 & $3.91<.001$ & $80.9,249.4$ \\
Presence of coach (0,1) & 108.5 & 86.0 & .135 & 1.26 & ns & $-63.0,280.0$ \\
Log number of speed games & 37.6 & 37.9 & .107 & 0.99 & ns & $-38.1,113.3$
\end{tabular}

Note. $R=.487, R^{2}=.237$, Adjusted $R^{2}=.203, F(3,68)=7.035, p<.001$. 
Table 4. Multiple regression predicting national rating using practice (players 40 years old or older).

\begin{tabular}{lrrrrrr}
\hline Variable & B & SE & Beta & t & $\mathrm{p}$ & $95 \% \mathrm{Cl}$ \\
\hline Constant & 1525.0 & 104.9 & & 14.5 & $<.001$ & $1305.5,1744.4$ \\
Log number of books & 185.1 & 67.3 & .474 & 2.7 & $<.05$ & $44.3,325.9$ \\
Presence of coach (0,1) & 94.3 & 75.7 & .214 & 1.2 & $\mathrm{~ns}$ & $-64.2,252.7$ \\
Log number of speed games & 93.1 & 44.7 & .334 & 2.08 & .051 & $-0.44,186.6$
\end{tabular}

Note. $R=.725, R^{2}=.526$, Adjusted $R^{2}=.451, F(3,19)=7.036, p<.005$. 


\section{Figure captions}

Figure 1: Group practice as a function of age and chess level. The mean and standard deviations for each group calculated since 4 years of age were: Masters ( $M=10.6$, $S D=5.2)$; Experts $(M=6.6, S D=3.9)$; Intermediates $(M=3.4, S D=2.9)$. The mean and standard deviations for each group calculated since starting playing were: Masters $(M=13.0, S D=5.7)$; Experts $(M=9.4, S D=5.6)$; Intermediates $(M=6.2, S D=$ 4.8).

Figure 2: Individual practice as a function of age and chess level. The mean and standard deviations for each group calculated since 4 years of age were: Masters ( $M$ $=7.3, S D=4.6)$; Experts $(M=3.7, S D=3.6)$; Intermediates $(M=2.6, S D=3.5)$. The mean and standard deviations for each group calculated since starting playing were: Masters ( $M=8.7, S D=4.6)$; Experts $(M=6.3, S D=6.9)$; Intermediates $(M=$ $4.4, S D=6.4)$.

Figure 3: Cumulative group practice as a function of years of serious practice, for the first ten years of serious practice. Note that the number of participants varies from year to year. The first year of practice was calculated over 17 masters, 35 experts, and 31 intermediates and the tenth year of practice was calculated over 15, 22 and 17 participants, respectively. Bars represent the standard errors of the mean.

Figure 4: Cumulative individual practice as a function of years of serious practice, for the first ten years of serious practice. Note that the number of participants varies from year to year. The first year of practice was calculated over 17 masters, 35 experts, and 31 intermediates and the tenth year of practice was calculated over 15, 22 and 17 participants, respectively. Bars represent the standard errors of the mean.

Figure 5: Variability in national rating as a function of cumulated individual practice. The mean and standard deviation of number of hours of individual practice in each 
group were: group 1: $M=10.4, S D=33$; group 2: $M=473, S D=244$; group 3: $M=$ $1,165, S D=348$; group 4: $M=2,293, S D=286$; group 5: $M=3,567, S D=529$; group 6: $M=5,317, S D=829$; group 7: $M=6,911, S D=306$; group 8: $M=9,963, S D=$ 2,276; group 9: $M=18,683, S D=3,075$.

Figure 6: Variability in national rating as a function of cumulated group practice. The mean and standard deviation of number of hours of group practice in each group were: group 1: $M=894, S D=444$; group 2: $M=2,000, S D=517$; group 3: $M=$ 3,494, $S D=408$; group 4: $M=4,841, S D=423$; group 5: $M=6,365, S D=371$; group 6: $M=8,117, S D=784$; group 7: $M=10,314, S D=624$; group 8: $M=13,744, S D=$ 2,126; group 9: $M=23,030, S D=7,358$.

Figure 7: International rating in masters and experts as a function of years since starting playing seriously. Bars indicate standard deviations.

Figure 8: International rating in masters and experts as a function of age. Bars indicate standard deviations.

Figure 9: Percentage of players with international rating as a function of years since starting playing seriously. Note that all the masters who are in the international list after seven years of serious playing have more than 2200 points.

Figure 10: Percentage of players with international rating as a function of age. Note that all the masters who are in the international list after 18 years of age have more than 2200 points. 
Figure 1.

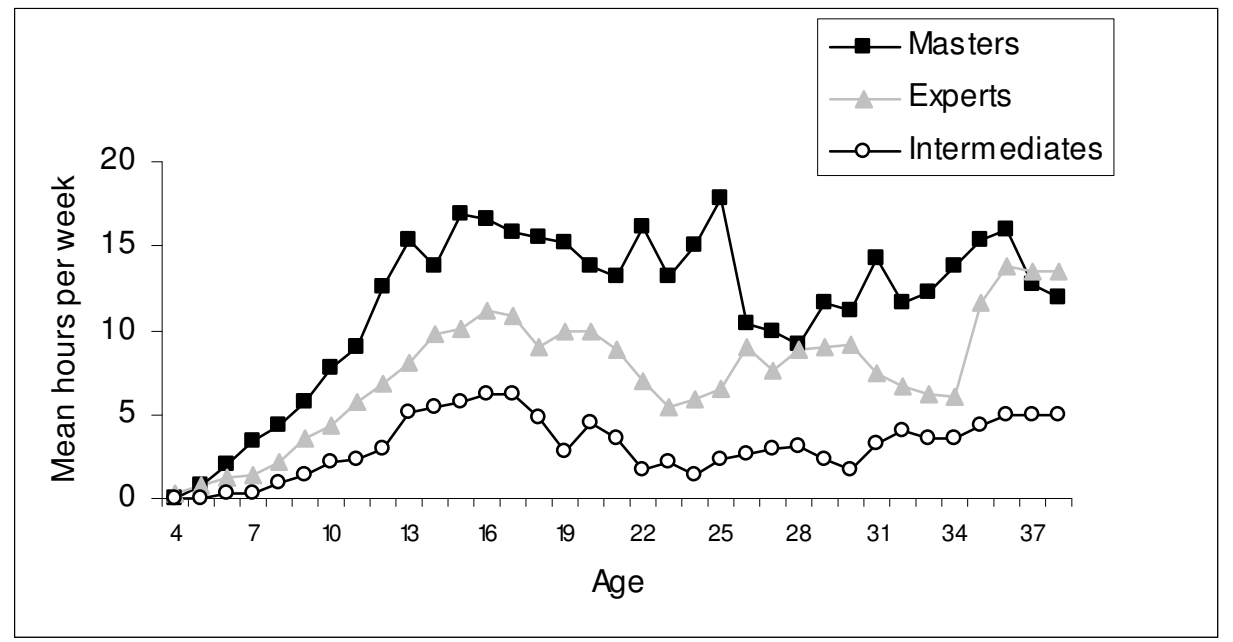


Figure 2.

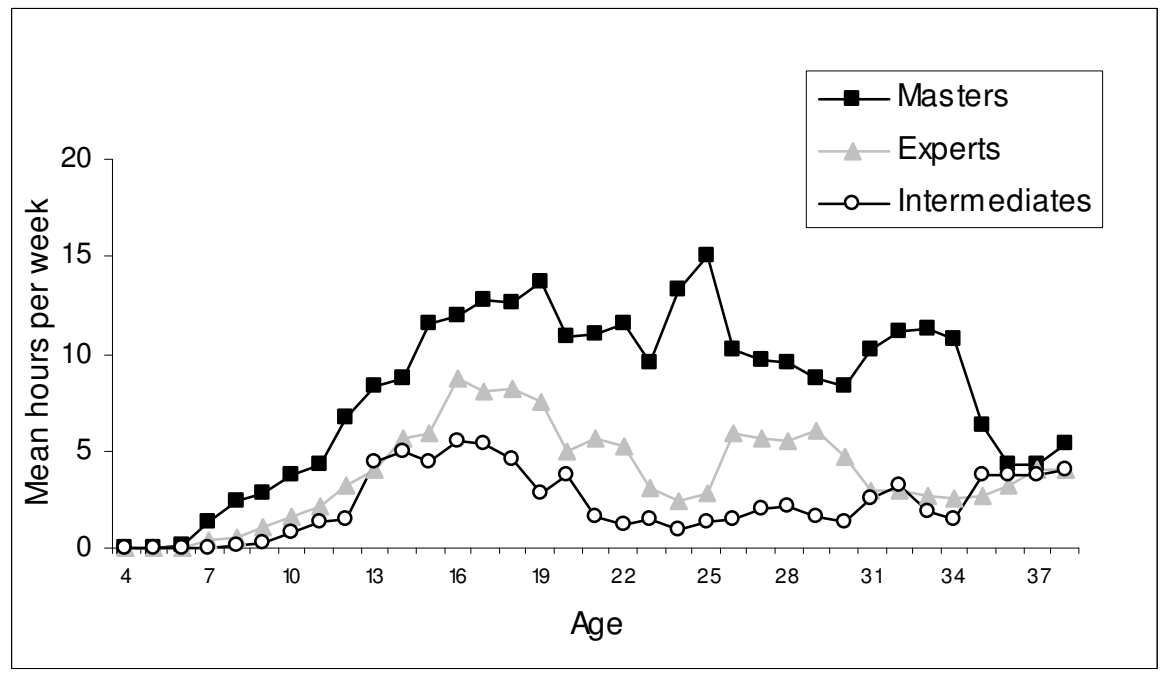


Figure 3.

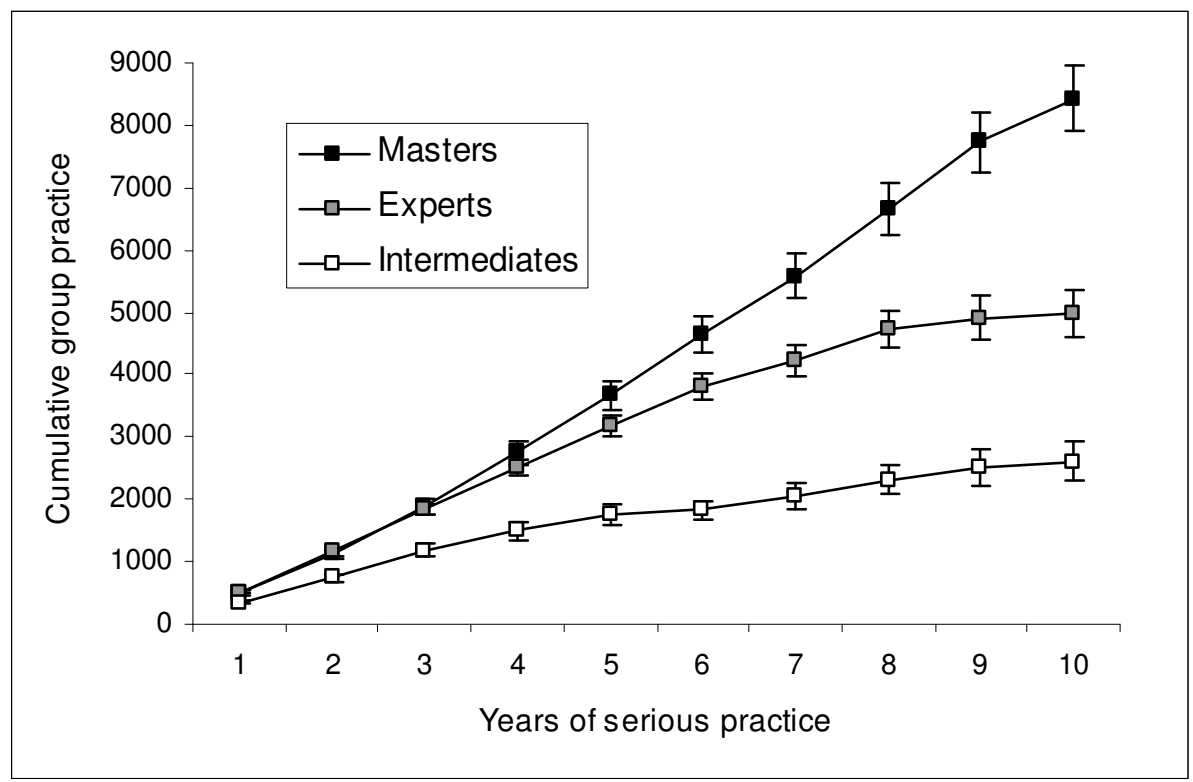


Figure 4.

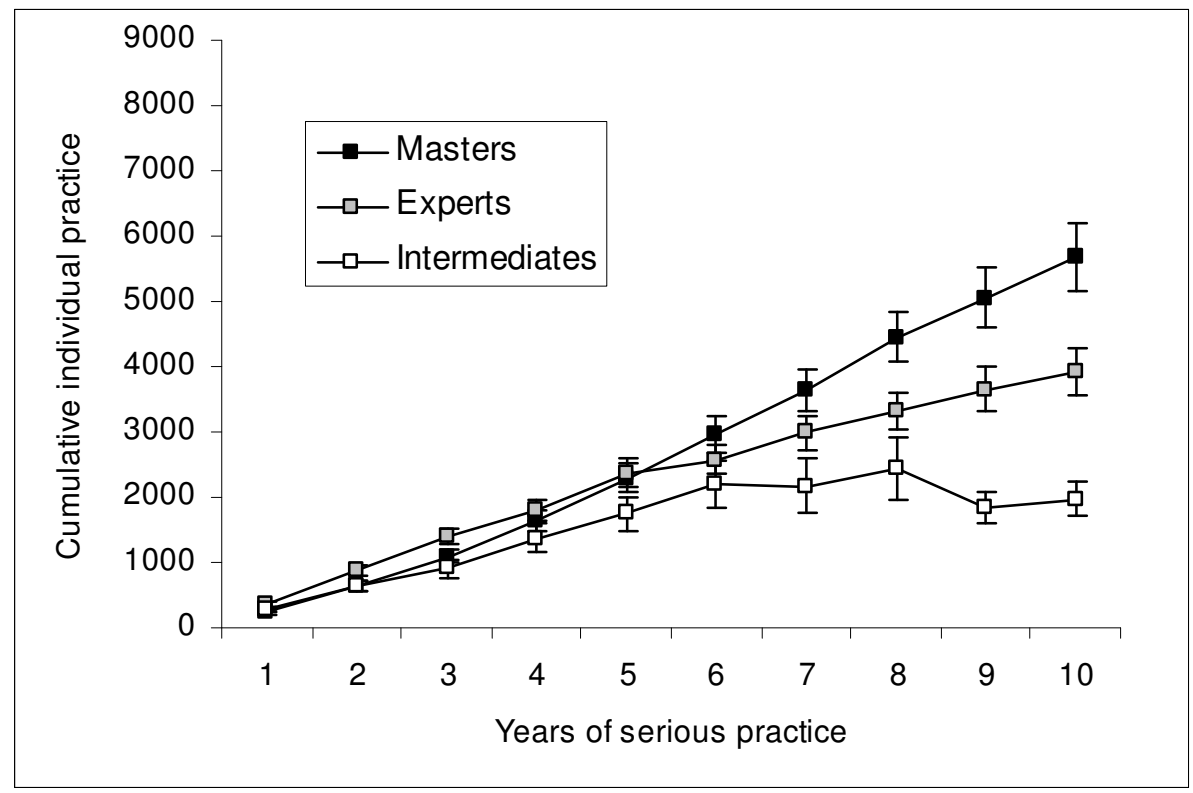


Figure 5.

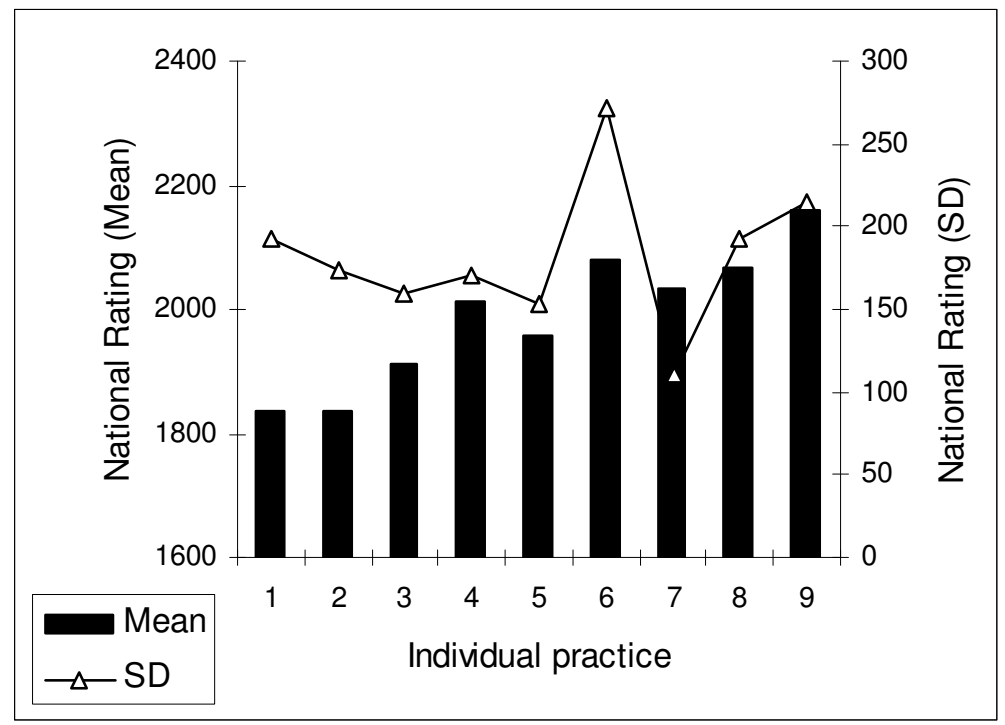


Figure 6.

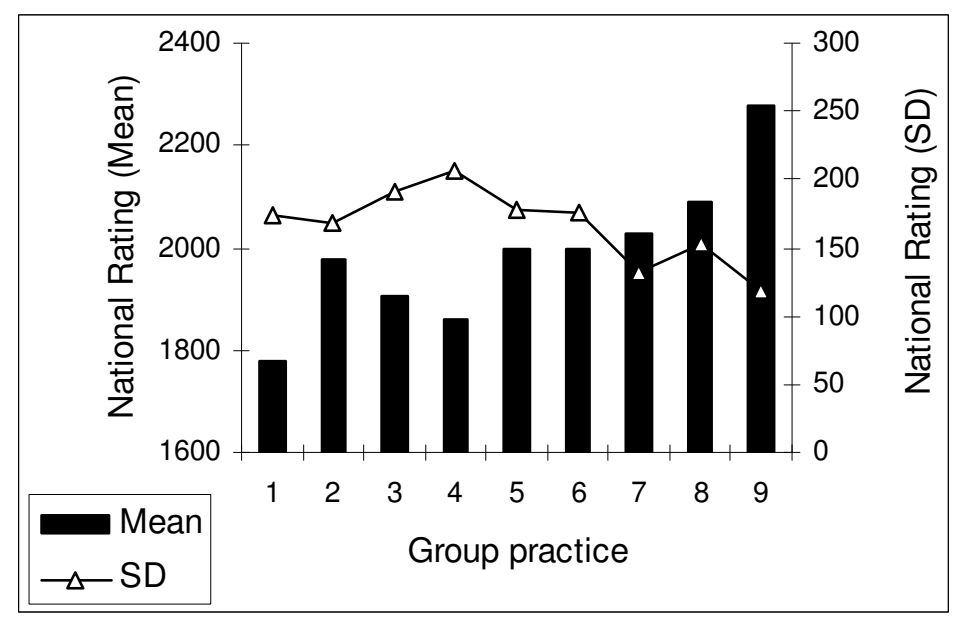


Figure 7.

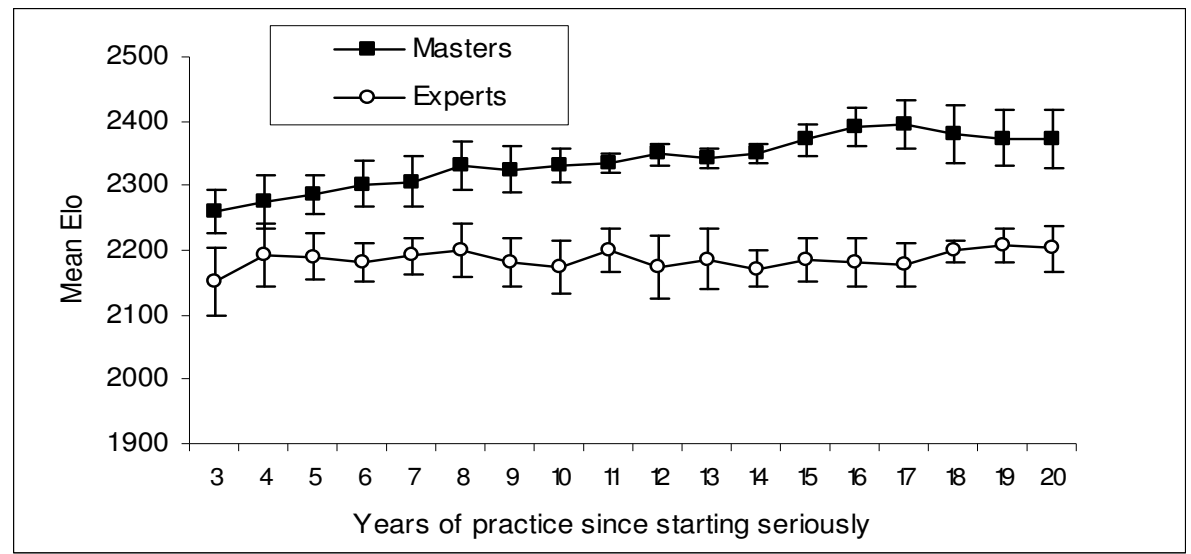


Figure 8.

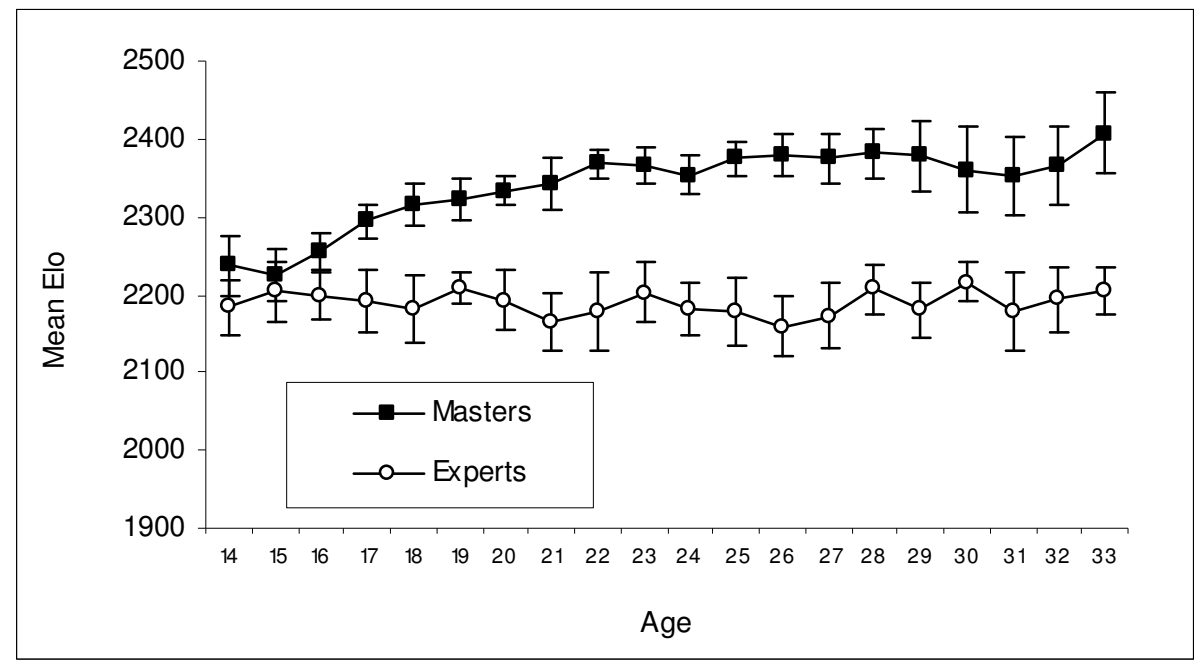


Figure 9.

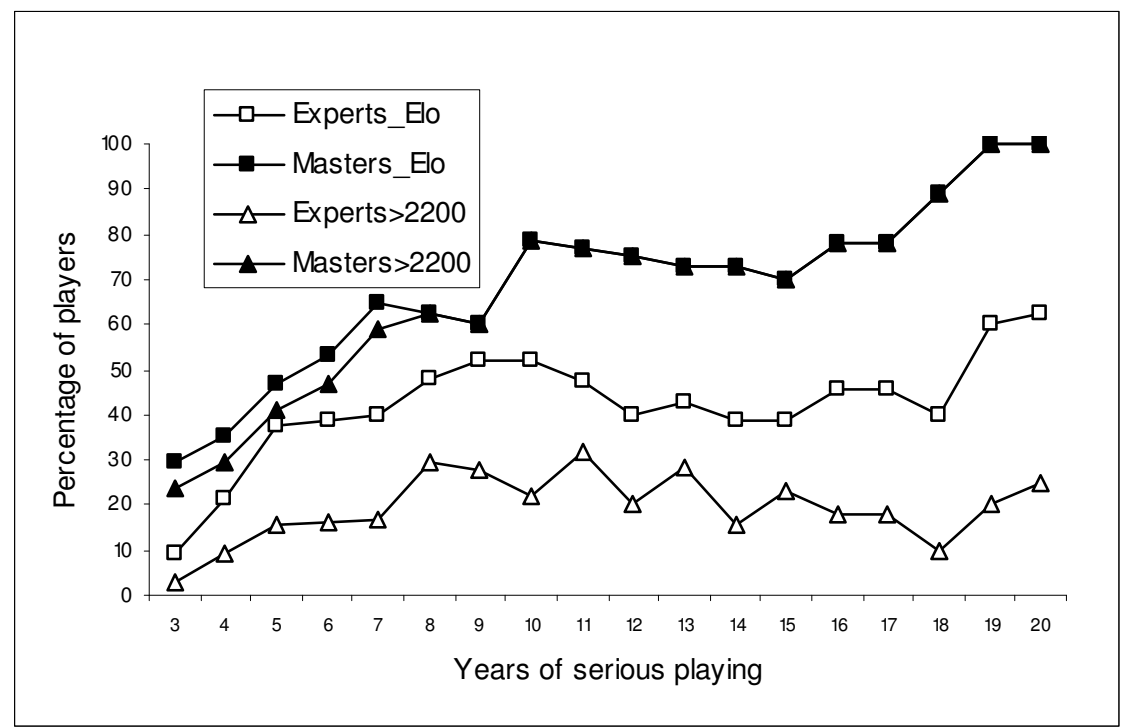


Figure 10.

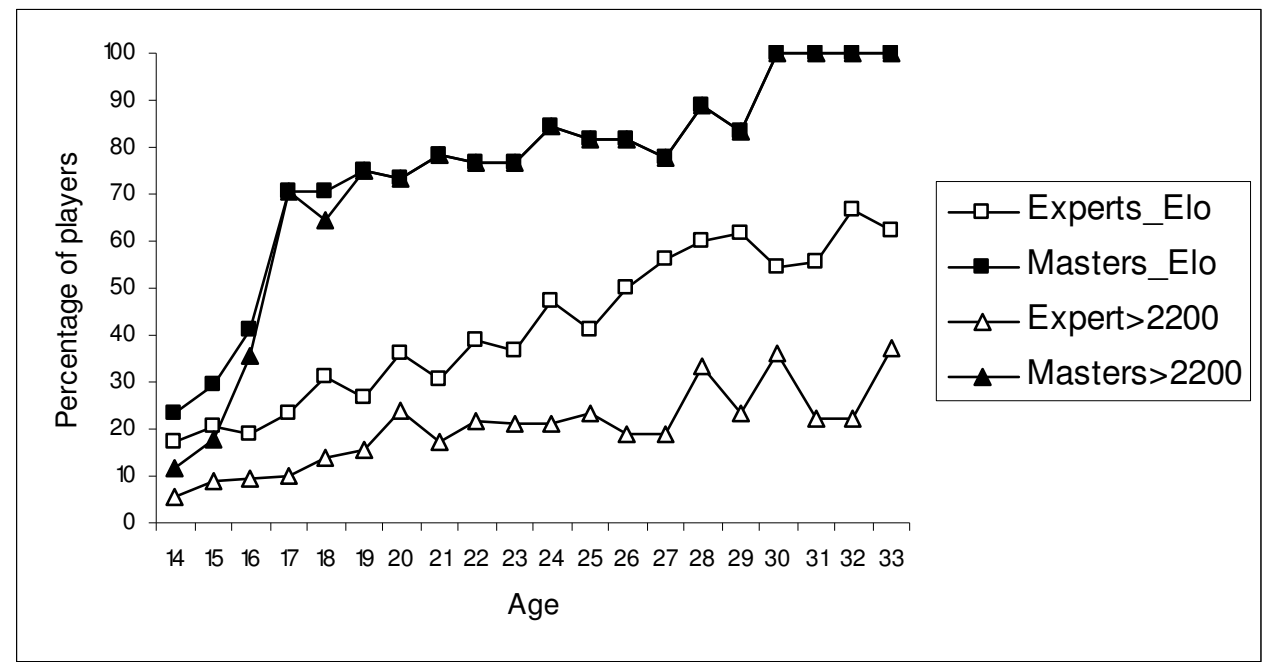




\section{Authors' note}

We thank Merim Bilalić, Neil Charness, Richard Smith, and anonymous reviewers for comments on this paper.

Correspondence concerning this article should be addressed to Fernand Gobet, Centre for the Study of Expertise, Brunel University, Uxbridge, Middlesex, UB8 3PH, United Kingdom. Email: fernand.gobet@ brunel.ac.uk 


\section{Footnotes}

${ }^{1}$ FIDE stands for Fédération Internationale des Échecs (International Chess Federation).

${ }^{2}$ The speed chess rating is computed independently from the national rating. In some cases, the calculation for the former rating is based on more than one thousand games.

${ }^{3} \mathrm{We}$ included tournament games under the umbrella of group practice, as players in Charness et al.'s study (1996, Table 2.4) considered active participation in chess tournaments as the most relevant activity.

${ }^{4}$ Charness et al. (2005) found that the relation between skill level and practice activities was moderated by age. This was the case in our sample as well with respect to the relation between rating and individual or group practice, as the correlations were stronger for older players, although, critically, they were always higher for group practice than individual practice. For the players below 40 years of age, the correlations were $r(69)=.36, p<.005$, for individual practice, and $r(68)=.55, p<$ .001 , for group practice. The respective correlations for players of 40 years of age and above were: $r(21)=.59, p=.005$, and $r(21)=.72, p<.001$.

${ }^{5}$ Note also that, although the skill levels are broken down in slightly different ways, the data in Figure 4 are in close agreement with those presented in Figure 1 in Charness et al. (2005). This common pattern suggests that the data of our study are generalisable (see also the Discussion section). 